\title{
Reversible, Two-Step Single-Crystal to Single-Crystal Phase Transitions between Desloratadine Forms I, II, and III
}

Published as part of a Crystal Growth and Design virtual special issue Remembering the Contributions and Life of Prof. Joel Bernstein

Vijay K. Srirambhatla, Rui Guo, Daniel M. Dawson, Sarah L. Price, and Alastair J. Florence*

Cite This: Cryst. Growth Des. 2020, 20, 1800-1810

Read Online

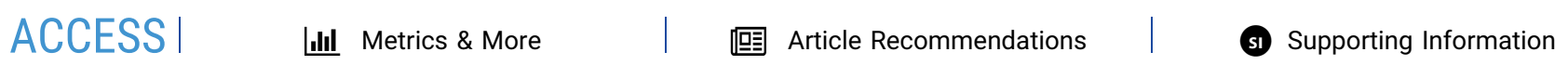

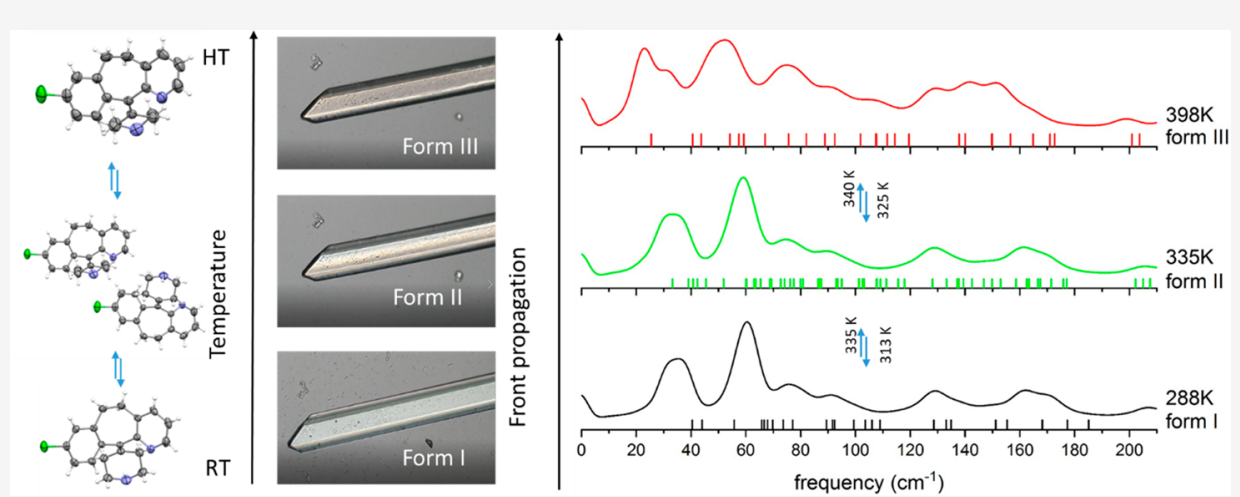

ABSTRACT: Single-crystal to single-crystal polymorphic transformations in molecular solids are relatively rare, with changes in crystal structure more commonly leading to destruction of the parent crystal. However, the structural basis for such transitions is of considerable interest given the changes in material properties that can result. The antihistamine desloratadine displays a two-step, reversible single-crystal to single-crystal phase transition during heating/cooling cycles between three conformational polymorphs: the low temperature form I, a polytypic intermediate form II, and the high temperature form III. The two-step transition involves a sequential flipping of the piperidine rings of desloratadine molecules in the crystals, which induce reversible micrometer-scale contraction on heating and expansion on cooling of the largest face of a desloratadine single crystal. Distinct, slow-moving phase boundaries, originating on the (001) face of the crystal, were observed sweeping through the entire crystal in hot-stage microscopy, suggesting a single nucleation event. Computational spectroscopy, using periodic DFT-D phonon calculations, reproduces the experimental variable-temperatureTHz-Raman spectra and rules out the possibility of the phase transformations occurring via any classical soft mode. A combination of variable-temperature powder X-ray diffraction, solid-state NMR, and computational spectroscopy provides a detailed molecular description of the phase transitions, indicating a first-order diffusionless process between I $\rightarrow$ II and II $\rightarrow$ III, wherein both conformational changes and lattice distortions occur simultaneously in the crystal lattice. The study indicates that a nucleation and growth mechanism is compatible with concerted movements producing a conformational change in organic molecular crystals.

\section{INTRODUCTION}

Understanding polymorphism and phase transformations in molecular crystals is crucial to enable the effective manufacture and exploitation of this important class of materials. Polymorphism $^{1,2}$ describes the ability of a chemical compound to adopt different crystal packing arrangements. Conformational polymorphs contain molecular conformations that approximate different isolated molecule conformational minima. ${ }^{3-5}$ Polymorphism is ubiquitous ${ }^{4}$ and has been reported for foodstuffs, ${ }^{6}$ pigments, ${ }^{7}$ agrochemical products, ${ }^{8,9}$ and pharmaceuticals. ${ }^{10}$ While single-crystal to single-crystal transformations in molecular solids are relatively rare, the structural basis for such transitions is of considerable interest given the impact on key material properties that can result. Conversion between polymorphs can change numerous physical properties including density, solubility, electric conductivity, color, mechanical strength, and morphology. Depending on the application, it may be necessary to control such transformations to ensure consistent performance or to deliberately exploit them to realize structures with desirable functions.

Received: November 13, 2019

Revised: January 14, 2020

Published: January 16, 2020 
However, despite ongoing research, it remains challenging to predict specific occurrences of polymorphism, ${ }^{11}$ let alone know which polymorphs can readily interconvert, for example, by a single-crystal to single-crystal polymorphic transformation.

The term "dynamic molecular crystals" has been applied to polymorphs where changes in physical properties can be controlled by external stimuli such as heat, light, or electric field. ${ }^{12}$ Despite the discovery of a number of molecular crystals that change structure under external stimuli, ${ }^{12-14}$ the design of new crystalline materials that can transmit molecular-scale structural changes to desirable macroscopic changes in crystal shape, while keeping their crystallinity throughout the transition, ${ }^{15,16}$ remains a significant challenge in organic crystal engineering. In particular, the transformation mechanisms involved are generally ill-defined and poorly understood. ${ }^{17}$ This is largely because direct observation of the molecular processes at or near the critical transition point is challenging, owing to the absence of suitable analytical techniques with sufficient spatial and temporal resolution. The thermodynamic, $^{18}$ structural, $^{19}$ and other classifications ${ }^{20}$ for phase transitions were largely developed for inorganic materials, and there is increasing evidence that they do not adequately capture the phenomena occurring in molecular crystals, ${ }^{21,22}$ particularly for molecules that have very nonspherical shapes, anisotropic intermolecular interactions, and sufficient flexibility to change conformation. ${ }^{23}$

Desloratadine (DES) is an antihistamine drug commonly used in the treatment of allergic reactions. ${ }^{24}$ The molecular structure of DES contains a piperidine ring attached to a $\mathrm{N}$ substituted dibenzazepine (NDBA) moiety (Figure 1).

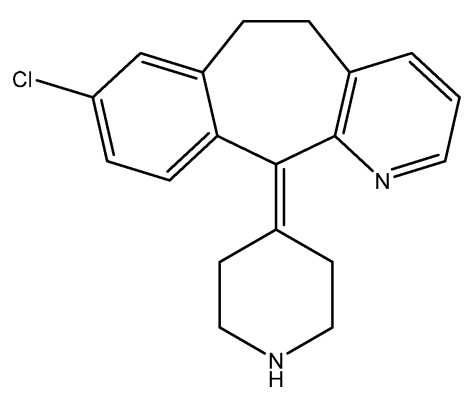

Figure 1. Molecular structure of DES.

Reported solid forms of DES include form $\mathrm{I}^{25}$ (CSD refcode: GEHXEX) and a benzoate salt (CSD refcode: DEGNOV). ${ }^{26}$ While the existence of a high temperature form is known, ${ }^{27}$ no crystal structure has thus far been reported. In the present work, reversible conformational phase transitions of DES are investigated using an array of experimental and computational methods to probe the structural and energetic changes in this system. Hot-stage optical microscopy has also revealed unusual features associated with the mechanism of transformation as well as macroscopic and reversible shape change in DES crystals undergoing phase transformations. The striking and unusual nature of phase transformations in DES is detailed while also highlighting the complexity associated with understanding solid-solid phase transformations in industrially relevant organic molecular materials.

\section{EXPERIMENTAL SECTION}

2.1. Crystal Structure Prediction and Periodic DFT-D Calculations. The complete details of crystal structure prediction studies are given in Supporting Information, Sections 2.2 and 2.3. The eight low-energy conformations of DES were determined by optimization at PBE0/6-31G(d,p) level using GAUSSIAN09 ${ }^{28}$ and the charge density analyzed by GDMA2.0 $0^{29}$ to give a distributed multipole model for the electrostatic interactions. These conformations were used to generate hypothetical structures using CrystalPredictor2.1, ${ }^{30}$ and the crystal structures were refined using Crystal Optimizer $2.4,{ }^{31}$ using the ab initio relative molecular energies, the distributed multipoles, and the FIT exp- 6 potential ${ }^{32}$ to allow all the bond angles and torsions to respond to the packing forces.

Periodic density functional calculations of lattice energy optimizations were performed with the PBE functional, ${ }^{33}$ with various dispersion corrections, ${ }^{34-36}$ using CASTEP17.2.2. ${ }^{37}$ The harmonic phonons were calculated by finite displacements using the PBE-TS functional and using supercells to sample the Brillouin zone.

2.2. Crystallization of DES. DES (8-chloro-11-(piperidin-4ylidene)-6,11-dihydro-5H-benzo[5,6]cyclohepta $[1,2-6]$ pyridine) and anhydrous ethyl acetate was procured from Sigma-Aldrich. Single crystals of DES were obtained by dissolving $\sim 100 \mathrm{mg}$ of DES in $\sim 2-$ $3 \mathrm{~mL}$ of ethyl acetate solvent and allowing the solution to evaporate slowly at RT. Colorless crystals that appeared after 5-8 days were used for subsequent analysis.

2.3. Differential Scanning Calorimetry (DSC). DSC measurements were performed on polycrystalline material using a Netzsch DSC214 Polyma differential scanning calorimeter. The samples were weighed into aluminum DSC pans and crimped with a pinhole in the lid. The samples were analyzed over the temperature range RT to 450 $\mathrm{K}$ at heating rates of $5,10,15$, and $40 \mathrm{~K}$ per minute.

2.4. In-Situ Variable Temperature Powder X-ray Diffraction. Powder X-ray diffraction data of the polycrystalline material were collected using a Bruker AXS D8-diffractometer. Finely ground DES form I was loaded into a $0.7 \mathrm{~mm}$ borosilicate glass capillary and mounted on the diffractometer operating in transmission geometry, equipped with a Johansson monochromator using $\mathrm{Cu} \mathrm{K} \alpha$ radiation $(\lambda$ $=1.5406 \AA$ A) and Lynxeye detector. An Oxford Cryosystems Cryostream was used to control the temperature of the sample prior to data collection. Variable temperature diffraction data were collected in the temperature range $150-380 \mathrm{~K}$. Data were collected over the angular range $3 \leq 2 \theta /^{\circ} \leq 50$, in $0.01^{\circ}$ steps, at a counting time of $1 \mathrm{~s} /$ frame increments of detector position. Quantification of polymorphs by Rietveld analysis ${ }^{38}$ was performed using TOPAS-V 5.0.

2.5. In-Situ Variable Temperature Single-Crystal X-ray Diffraction. The single crystal X-ray diffraction data were collected using $\mathrm{Mo}-\mathrm{K} \alpha$ radiation $(\lambda=0.7107 \AA)$, on a Bruker Apex-II diffractometer equipped with a CCD detector, controlled using APEX3 software. An Oxford Cryosystems cryostream was used to control the temperature of the crystals prior to data collection. Data integration and reduction were performed using the SAINT software (version $8.34 \mathrm{~A}){ }^{39}$ The crystal structures were solved by direct methods using the program SHELXS, ${ }^{40}$ and subsequent Fourier calculations and least-squares refinements were performed on $F^{2}$ using the program CRYSTALS. ${ }^{41}$ All non-hydrogen atoms were refined with anisotropic displacement parameters. All hydrogen atoms bonded to the carbon atoms were placed geometrically and refined with the isotropic displacement parameter fixed at 1.5 times $U_{\mathrm{eq}}$ of the atoms to which they are attached. Protons involved in hydrogen bonding were located directly via inspection of difference Fourier maps and were refined isotropically. The crystallographic data of DES polymorphs I, II, and III are provided in Supporting Information, Section 1.2.1. Face indexing of the DES crystals was performed using the Index Crystal Faces routine of Apex 3 software.

2.6. Temperature-Resolved Terahertz Raman Spectroscopy. Variable temperature Raman measurements was performed using the Ondax THz-Raman Spectroscopy Systems using a $785 \mathrm{~nm}$ laser. Variable temperature THz-Raman data on a single crystal of DES were collected between RT and $380 \mathrm{~K}$ during heating and cooling cycles in the extended spectral range of $0-1700 \mathrm{~cm}^{-1}$. The sample temperature was controlled using a Linkam LST 420 hot-stage.

2.7. Hot-Stage Optical Microscopy. Temperature-resolved microscopic measurements were performed using a Leica DM6000 
FS microscope, equipped with Leica DFC 310 FX camera. A Linkam LTS 420 hot-stage, equipped with T95-Linkam control pad and T95 Linkam temperature controller unit, and an optional LNP95 liquid nitrogen cooling pump system were used to control the temperature of the crystals.

2.8. Temperature-Resolved Solid State NMR Spectroscopy. Solid-state NMR spectra were recorded on a Bruker Avance III spectrometer equipped with a wide-bore $9.4 \mathrm{~T}$ superconducting magnet (Larmor frequencies of 400.13 and $100.61 \mathrm{MHz}$ for ${ }^{1} \mathrm{H}$ and ${ }^{13} \mathrm{C}$, respectively). The sample was packed into a standard $4 \mathrm{~mm}$ zirconia rotor and rotated at the magic angle at $12.5 \mathrm{kHz}$. Spectra were acquired with cross-polarization (CP) from ${ }^{1} \mathrm{H}$ with a spin lock (ramped for $\left.{ }^{1} \mathrm{H}\right)$ of $5 \mathrm{~ms}$. High-power $\left(\nu_{1} \approx 100 \mathrm{kHz}\right)$ TPPM-15 decoupling of ${ }^{1} \mathrm{H}$ was applied during acquisition. Signal averaging was carried out for 24 transients with a recycle interval of $300 \mathrm{~s}$. The sample temperature was controlled using a Bruker BVT control unit, equipped with BCU-II chiller and BVTB-3000 heater booster. The sample was heated to the target temperature and then allowed to reach thermal equilibrium for $5 \mathrm{~min}$ before data acquisition. The sample temperature was calibrated using the hexagonal to fcc phase transition of DABCO $(351.1 \mathrm{~K})^{42}$ as a fixed temperature point and the temperature dependence of the ${ }^{87} \mathrm{Rb}$ chemical shift of $\mathrm{RbCl}$ to calibrate temperatures across the relevant range. ${ }^{43}{ }^{13} \mathrm{C}$ Chemical shifts are reported in ppm relative to $\left(\mathrm{CH}_{3}\right)_{4} \mathrm{Si}$ using the $\mathrm{CH}_{3}$ resonance of L-alanine $(\delta=20.5 \mathrm{ppm})$ as a secondary solid reference.

\section{RESULTS}

As part of the investigation into polymorphism of DES, a crystal structure prediction (CSP) ${ }^{44}$ study was performed (Supporting Information, Section 2.2). The progress in CSP methods in recent years ${ }^{11,45}$ has reached the stage where it is starting to inform experimental screening approaches ${ }^{46,47}$ to allow targeted crystallization of computationally predicted polymorphs. ${ }^{48-51}$ Conformational analysis of a DES molecule in the gas phase resulted in eight conformational minima within $4 \mathrm{~kJ} / \mathrm{mol}$ of the global minimum (Supporting Information, Section 2.1). These were used in the CSP search, which was also constrained to only consider $Z^{\prime}=1$ structures. The search (Supporting Information, Section 2.2) revealed two densely packed, dispersion bound structures, the most stable being form I and a higher energy structure that was later shown to be form III. The other low energy structures were less dense, and most were based on $\mathrm{N}-\mathrm{H} \cdots \mathrm{N}$ hydrogen-bonded molecular chains. Alternative evaluations of the relative stability of the CSP generated structures suggested that the hydrogen-bonded structures were thermodynamically less likely than form I and III (Supporting Information, Section 2.3). Hence, the CSP study did not suggest any further conformational or packing polymorphs to be targeted.

3.1. Differential Scanning Calorimetry (DSC). DSC analysis of polycrystalline DES I exhibits two endothermic transitions upon heating with peak temperatures of 338.6 and $431.3 \mathrm{~K}$ (Figure 2). While the second endotherm is consistent with the melting of the compound, the first endotherm with an onset of $334.8 \mathrm{~K}$ can be attributed to successive solid-solid phase transformations, i.e., overlapping signals from the conversion of DES I $\rightarrow$ II and II $\rightarrow$ III (based on diffraction data) (Section 2.2 and 2.3). Indeed, upon cooling from $375 \mathrm{~K}$, the thermogram exhibits two exothermic transitions with onset temperatures of 326.5 and $313.9 \mathrm{~K}$ corresponding to polymorphic transformations of III $\rightarrow$ II and II $\rightarrow$ I. The enthalpy changes associated with the transformations III $\rightarrow$ II and II $\rightarrow$ I during the cooling cycle are $0.4 \pm 0.1$ and $0.3 \pm 0.1$ $\mathrm{kJ} / \mathrm{mol}$. According to the heat of transition rule proposed by Burger and Ramberger, ${ }^{52}$ if an endothermic transition is

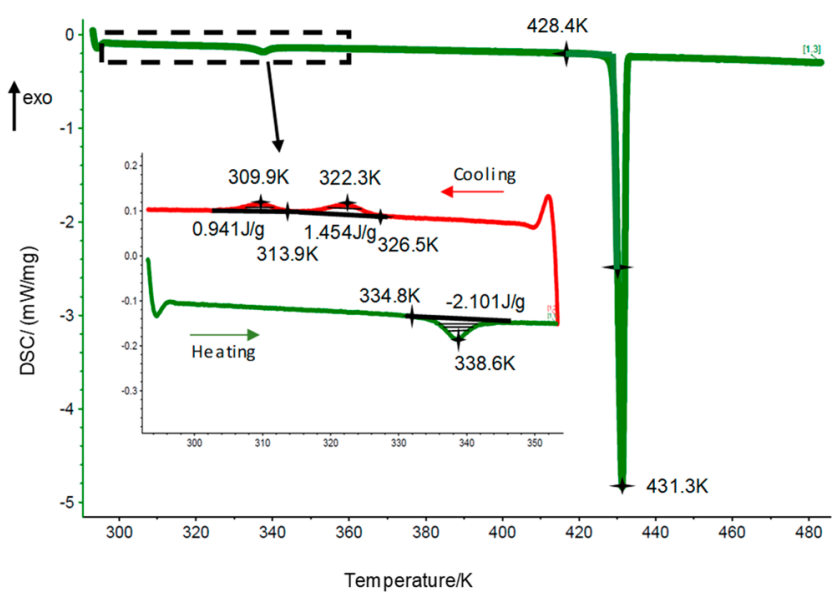

Figure 2. DSC curves of powder DES I, with a heating cycle in green. The insert shows the cooling cycle in red. Data collected at $5 \mathrm{~K} / \mathrm{min}$. The black lines indicate area under the curve.

observed before melting, the polymorphs are related enantiotropically. Repeated experiments between RT and $375 \mathrm{~K}$ with different heating and cooling rates (at 5-40 K/ min) resulted in similar thermal data confirming the reversible and reproducible nature of the phase transformations (Supporting Information, Figures S16-S19). The DSC data suggest that DES form I is the thermodynamically stable form at room temperature (RT) with II and III being enantiotropically related. While the exact onset of DES I $\rightarrow$ II and II $\rightarrow$ III phase transitions in the heating cycle are not clear, DSC analysis indicates a thermal hysteresis of $\sim 20 \mathrm{~K}$ based on the observed onset temperatures.

3.2. In-Situ Variable Temperature Powder X-ray Diffraction (VT-PXRD). A finely ground sample of recrystallized DES I was used to perform in situ VT-PXRD analysis. PXRD data were collected between 150 and $400 \mathrm{~K}$ for both the heating and cooling cycles. Representative X-ray diffraction data for forms I, II, and III are shown in Figure 3 with the

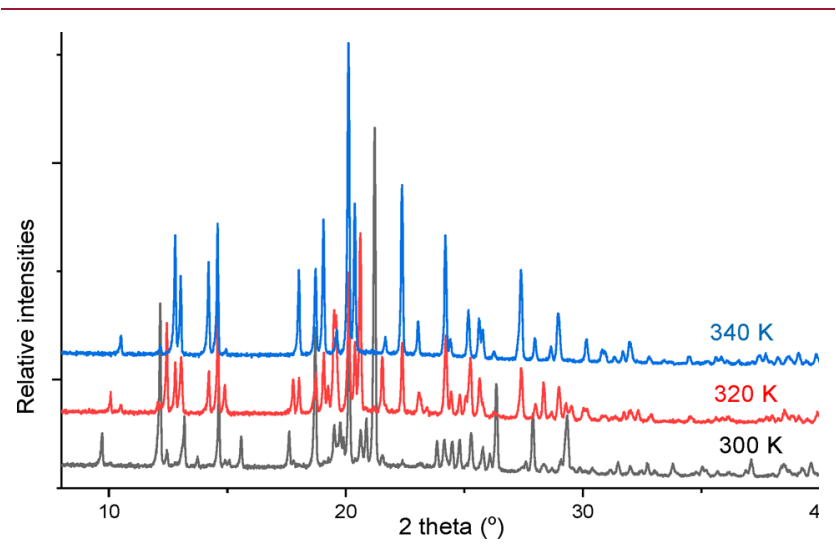

Figure 3. Selected powder XRD patterns at different temperatures during a cooling cycle. At $340 \mathrm{~K}$ (DES III, blue), $320 \mathrm{~K}$ (DES II, red), and at $300 \mathrm{~K}$ (DES I, black).

complete data sets in Supporting Information, Section 1.3. The PXRD data indicate that, upon heating, form I transforms to II and then to III. Upon cooling, the reverse transformations of III to II and then to I were observed. All three phases are observed to coexist over a range of temperatures: visual inspection of the VT-PXRD data indicates the phase 


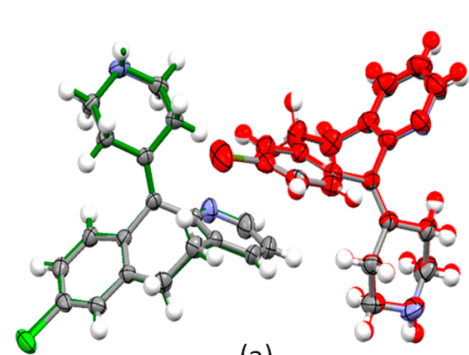

(a)

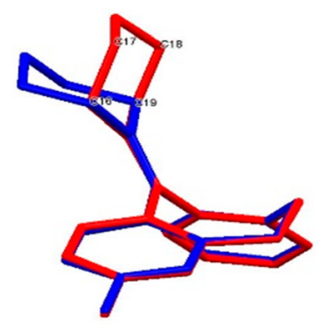

(b)
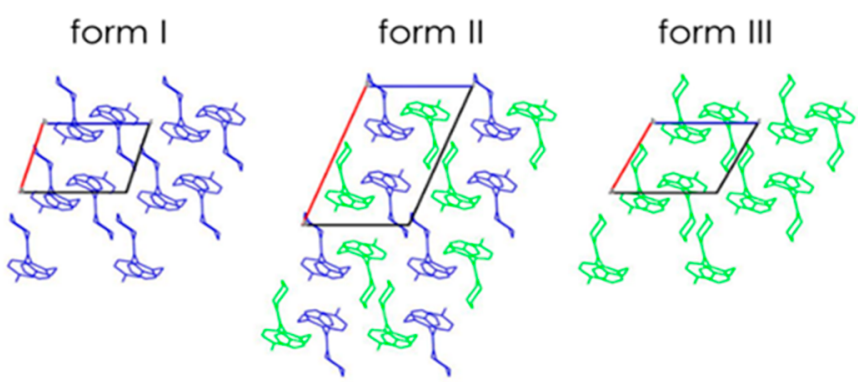

$b$ axis
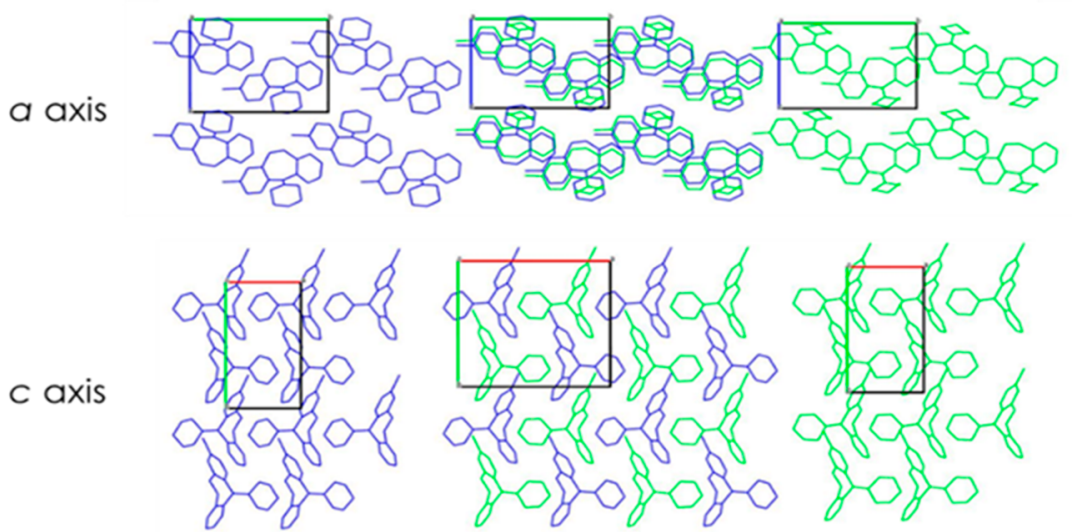

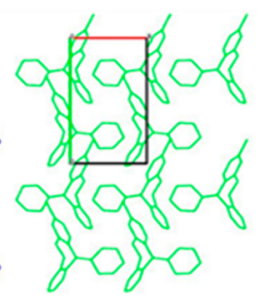

(c)

Figure 4. (a) Superimposition of asymmetric units of form I (green $Z^{\prime}=1$ ), II (gray $Z^{\prime}=2$ ), and III (red $Z^{\prime}=1$ ), (b) overlay of the molecular conformations AAA (blue) and ASE (red) in DES I and DES III, (c) crystal packing arrangements of DES I $\left(P 2_{1}, a=7.061 \AA \quad b=12.070 \AA c=\right.$

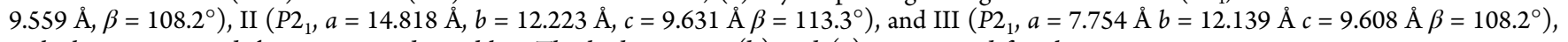
with the $a$ axis in red, $b$ in green, and $c$ in blue. The hydrogens in (b) and (c) are omitted for clarity.

transformations in the powder between forms I to III extend over $\sim 15 \mathrm{~K}$ in the heating cycle and $\sim 25 \mathrm{~K}$ during the cooling cycle, consistent with the DSC and variable temperature solidstate NMR (VT-SS-NMR Supporting Information, Section 1.6) measurements. More quantitative measurements (see Section 2.5) indicate that phase transformations between forms I and III occur across a wider temperature range of over $40 \mathrm{~K}$.

3.3. In-Situ Variable Temperature Single Crystal X-ray Diffraction. Variable temperature single crystal X-ray diffraction (VT-SXRD) was used to track the specific structural changes in individual crystals. Starting with a single crystal of form I, single crystal X-ray diffraction data were obtained at 80 $\mathrm{K}, 293 \mathrm{~K}, 320 \mathrm{~K}, 335 \mathrm{~K}$, and $350 \mathrm{~K}$ during heating and then at $320 \mathrm{~K}, 315 \mathrm{~K}$, and $293 \mathrm{~K}$ during cooling to explore the sequence of structural transitions.

Investigating the reciprocal lattice planes at different temperatures indicated that additional reflections that do not index with form I unit cell parameters appear at $\sim 320 \mathrm{~K}$ (Supporting Information, Section 1.2.3), before the onset of phase transformation to II expected at $\sim 335 \mathrm{~K}$ from DSC. The intensity and number of these reflections increase on approaching the onset of the DSC derived transition temperature. Structure determination at $335 \mathrm{~K}$ demonstrates that single crystal has transformed with two molecules in the asymmetric unit and the length of the " $a$ " axis doubling in size. One molecule is in the AAA conformation, and the other is in the ASE conformation (where the piperidine ring and the C6 carbon of the NDBA moiety are in the "syn" orientation), which is nearly equi-energetic with the AAA conformation (Supporting Information, Section 2.1). The two molecules in the asymmetric unit of form II are connected by weak $\mathrm{C}-\mathrm{H} \cdots$
$\mathrm{N}$ interactions $(\mathrm{C} \cdots \mathrm{N}=3.369$ (2) and 3.360 (3) $\AA$ ), which arrange to form $1 \mathrm{D} \mathrm{H}$-bonded chains extending along the $b$ axis. Form II was always observed in the presence of either form I (on the heating cycle) or form III (on the cooling cycle), suggesting that fragments of the crystal had not yet transformed at the measurement temperature.

On heating above $335 \mathrm{~K}$, the DES form II crystal subsequently transforms to a high temperature phase, form III. Structure determination at $350 \mathrm{~K}$ in space group $P 2_{1}$ yields one molecule in the asymmetric unit in the ASE conformation, highlighting that all molecules in the lattice have changed conformation. Upon cooling from $350 \mathrm{~K}$, form III crystals transform back to form II at $320 \mathrm{~K}$, which subsequently transforms to form I at $293 \mathrm{~K}$ confirming that both transformations are reversible. The VT-SXRD results show the transition between forms I, II, and III is a completely reversible, two-step single-crystal to single-crystal, solid-state transformation. A number of SXRD measurements with crystals of different sizes resulted in similar observations with form II as the intermediate structure. The single particle transformation mechanisms and transitions are consistent with those observed from the bulk samples. It is also notable from both single crystal and PXRD data for DES II that diffraction from DES I (heating) or III (cooling) was always present. This is likely due to hysteresis in nucleation of individual crystallites in the polycrystalline samples or untransformed domains within the single crystal.

Despite the conformational change of the piperidine ring involved in each phase transformation, all three polymorphs contain similar packing arrangements. Overlays of the asymmetric units (molecules) in the three structures indicate a conformational change analogous to a chair inversion in 
piperidines (Figure 4b). Thus, the three DES structures reported here are clearly conformational polymorphs ${ }^{3-5}$ with form II being a polytypic ${ }^{53}$ arrangement of alternating layers of I and III. Owing to the close similarity in crystal packing arrangements of all the three forms, there is a close orientational relationship between the unit-cell parameters of forms I, II, and III as measured with the TOPO software ${ }^{54}$ (Supporting Information, Section 1.2.5). A direct comparison of unit cell parameters of the three polymorphs shows that the $a$ axis doubles, the $b$ axis expands, while the $c$ axis insignificantly contracts during the I $\rightarrow$ II phase transformation (Supporting Information, Section 1.2.4). Also, during the II $\rightarrow$ III transformation the $a$ axis halves, while the $b$ and $c$ axes expand over this temperature range. Additionally, the angle $\beta$ sequentially increases from form I to II to III $\left(108.08^{\circ}\right.$, $113.38^{\circ}$, and $118.78^{\circ}$ respectively). The refined Flack parameter values (Supporting Information, Section 1.2.1) at different temperatures indicate that the reversible transformation occurs without a change in the handedness of the crystals. The mosaicity $(\sim 0.59 \pm 0.02)$ of the crystal also remains constant over the heating and cooling cycles, suggesting no significant change in individual crystal quality.

3.4. Variable Temperature THz Raman. Lattice dynamics are of central importance to understand the mechanism of solid-solid phase transformations and material properties. Terahertz $(\mathrm{THz})$ spectroscopic $^{55}$ techniques can readily measure the phonon modes at the Brillouin zone center, and so temperature resolved $\mathrm{THz}-\mathrm{low}$ frequency Raman measurements on a single crystal of DES were performed to investigate the mechanism of reversible phase transformation. The evolution of the low-frequency Raman spectra as a function of temperature is measured under nitrogen atmosphere during the heating and cooling cycles over the extended spectral range $0-1700 \mathrm{~cm}^{-1}$ (Supporting Information, Section 1.4). The representative low-frequency Raman spectra (below $210 \mathrm{~cm}^{-1}$ ) of DES I, II, and III (Figure 5) show substantial differences. Additionally, there is a progressive change in the Raman spectra with change in temperature accompanying the transformation of form I to form II and subsequently to form III (Supporting Information,
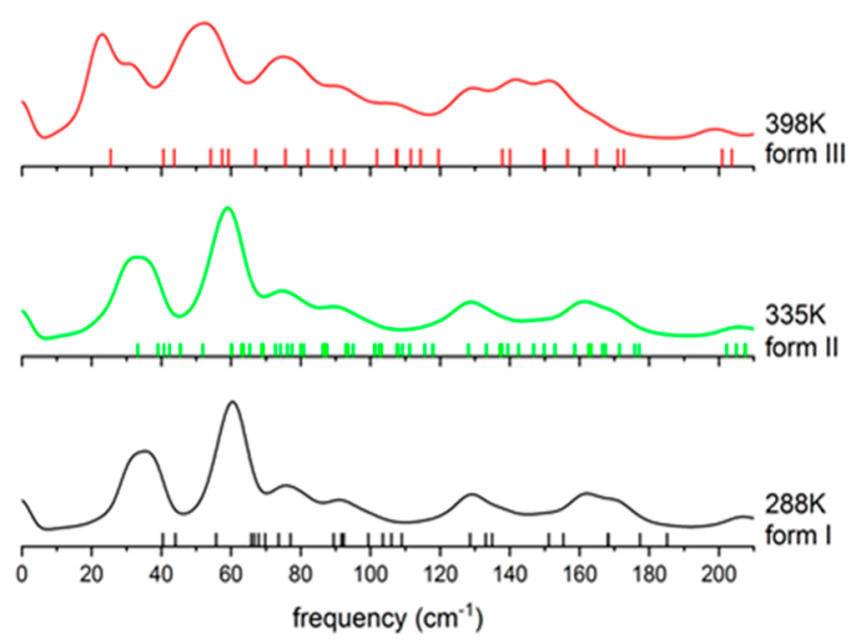

Figure 5. Low-frequency regions of the measured THz-Raman spectra of crystalline DES polymorphs I, II, and III. The markings at the bottom of each spectrum are the calculated $\Gamma$-point phonons of the respective polymorphs (Supporting Information, Section 2.5).
Section 1.4). The appearance and disappearance of vibrational modes confirm the reversible nature of the phase transformation. The spectrum of form I shows that several modes shift to lower frequency on heating, which reverses on cooling, which may be attributed to the changes in thermal vibrations. ${ }^{56}$ There is no evidence from the THz-Raman data of any transient amorphous or disordered intermediate phases during the heating/cooling cycles. ${ }^{57}$

While the $\mathrm{THz}$ Raman data are rich in information corresponding to both inter- and intramolecular vibrations, extracting relevant information is challenging without exploiting the recent development of computational methods. ${ }^{58,59}$ Theoretical harmonic phonon dispersion curves along highsymmetry paths of the Brillouin zone were calculated using periodic electronic structure (PBE-TS) methods (see Supporting Information, Section 2.4). Allowing for the expected offset between the calculated and observed modes in the $\mathrm{THz}$ region, the calculated and experimental modes match reasonably well (Figure 5), particularly considering the elevated temperatures at which the $\mathrm{THz}$ spectra were measured.

The free energy differences between the three forms were also estimated from the calculated modes and lattice energies (Supporting Information, Section 2.4). Form I was found to be the most thermodynamically stable form at lower $\mathrm{T}$, with form II being the next most stable in lattice energy, but the thermal contributions stabilize form III, such that form III becomes the most stable phase above about $380 \mathrm{~K}$. The energy differences between form I and III are in reasonable agreement with the DSC measurements, given the uncertainty in the lattice energies and the use of the harmonic approximation without allowance for thermal expansion. ${ }^{60}$ Form II is very thermodynamically competitive with the other forms around the transition region (Supporting Information, Figure S28).

Visual examination of the calculated $\mathrm{THz}$ modes in $\mathrm{Jmol}^{61}$ indicates strong mixing of inter- and intramolecular vibrations, and there is no single phonon mode that can be seen as a pathway for the phase transformations. The calculated phonon modes also indicate that all phonon frequencies are positive across the entire Brillouin zone (Supporting Information, Figure S27), implying that all three forms are stable and ruling out the possibility of either of the two phase transformations (I $\rightarrow$ II and II $\rightarrow$ III) occurring via a "soft" mode mechanism. ${ }^{62}$ This contrasts with the order-disorder phase transformation observed in camphor, where it was shown that one single lowfrequency mode was responsible for the phase transformation. ${ }^{63}$

The intensities and frequencies of several optical modes in the mid-infrared region of the Raman spectra also differ between the forms. These are in good agreement with the computed Raman spectra for the isolated molecule in the AAA and/or ASE conformations (Figure 6). The main differences in the Raman spectra are associated with the piperidine ring conformation. Comparison of the calculated Raman spectra suggests that a peak at $987.3 \mathrm{~cm}^{-1}$ can be used unambiguously as the fingerprint of the AAA conformation (Supporting Information, Section 2.6). This peak was used to quantify the proportion of the AAA conformation during heating and cooling and the accompanying phase transitions (Figure 7).

3.5. Quantifying and Interpreting DES Phase Transformations through Temperature Cycles. The progress of DES phase transformations through temperature cycles, as monitored through the percentage of molecules in the AAA conformation, from variable temperature Raman single-crystal 


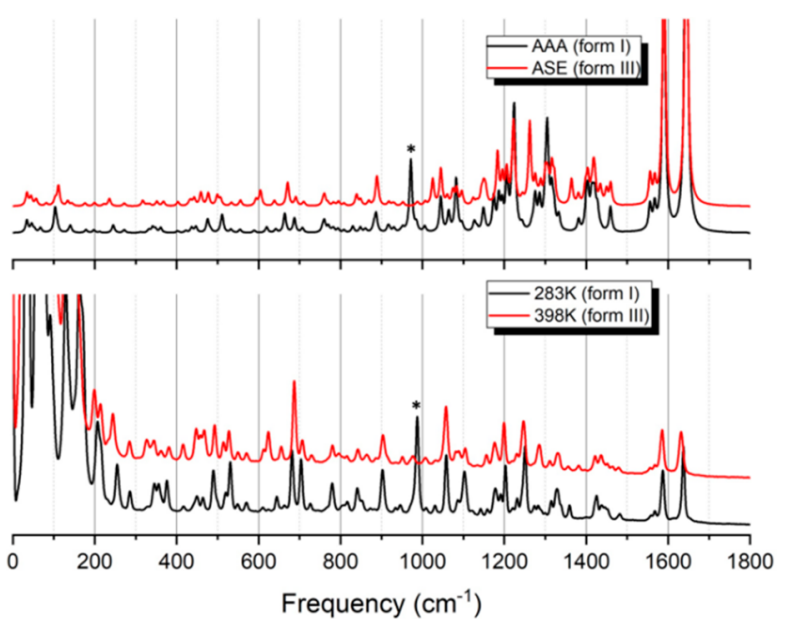

Figure 6. Comparison of (bottom) experimental THz-Raman spectra at two temperatures and (top) scaled calculated Raman spectra for an isolated molecule of DES in the AAA and ASE conformations. The peak (observed at $987.3 \mathrm{~cm}^{-1}$ ) marked with an asterisk is unique to the AAA conformation.

spectra, correlates well with that shown from the quantitative Rietveld analysis of variable temperature PXRD observations in Section 2.2 (Figure 7), Along with the other measurements on macroscopic samples including DSC (Section 2.1, Supporting Information, Section 1.5) and SS-NMR (Supporting Information, Section 1.6), this offers a molecular-level interpretation of different stages of DES phase transitions in both bulk powder and single crystal samples. It is clear that during heating form I first transforms to form II with the appearance of the ASE conformation. On the basis of the PXRD data, Form II reaches a maximum composition in the powder sample at $335 \mathrm{~K}(28 \%)$ after which the sample rapidly and completely converts to form III above $350 \mathrm{~K}$. This indicates that during the DSC heating measurements (Figure 2), the two phase transitions (I $\rightarrow$ II and II $\rightarrow$ III) overlap, probably due to hysteresis, resulting in a single observable endotherm $\left(T_{\text {onset }}=334.8 \mathrm{~K}\right)$. The temperature range over which conformational change is observed (black lines in Figure 7a) from the Raman measurements is in good agreement with the observed endothermic peak from DSC upon heating (Figure 2). During cooling, $\mathrm{THz}$ Raman revealed two stages for the molecular conformation changes, separated by an evident slow-down just before the AAA percentage reached 50\% (black lines in Figure $7 \mathrm{~b})$, again matching the observed transition temperatures by $\operatorname{DSC}\left(T_{(\mathrm{III} \rightarrow \mathrm{II})_{\text {onset }}}=326.5 \mathrm{~K}\right.$ and $\left.T_{(\mathrm{II} \rightarrow \mathrm{I}) \text { onset }}=313.9 \mathrm{~K}\right)$ (Figure 2). In the first stage, form III transforms to form II with the accompanying transformation of some ASE conformers to AAA, while some form II may have transformed to form I by the end of this stage. However, at $315 \mathrm{~K}$, form II is the main component (64\%) of the sample, with about $27 \%$ of untransformed form III and $9 \%$ completely transformed to form I. This is presumably down to different nucleation rates in different individual crystals in the sample and may result from differences in particle size and quality. At the end of the first stage $(315 \mathrm{~K})$, THz Raman showed a slow-down of conformation change, followed quickly by the second stage of transformation (from II $\rightarrow$ I), matching the second exothermic peak in DSC (Figure 2), along with any remaining III $\rightarrow$ II $\rightarrow$ I transformation resulting in the complete transformation of the sample to form I (and AAA conformation).

3.6. In-Situ Hot-Stage Microscopy. Crystals of DES form I were immersed in silicon oil and examined by hot-stage microscopy during heating and cooling between RT and 360 K. Upon heating, the crystal visibly changes shape (Figure 8, Supporting Information, Figures S1 and S3, Supporting Information Video_S1 and S2), and a continuous transverse wavefront can be observed, initiating from the $(00 \overline{1})$ face, that moves through the crystal as growth of the emergent phase proceeds. In the heating cycle, it has not been possible to attribute the observed optical phenomenon to either of the two possible transformations (I $\rightarrow$ II or II $\rightarrow$ III), due to the narrow temperature difference between successive transformations. Viewed perpendicular to the $(10 \overline{1})$ face, the width of the crystal between faces $(100)$ and $(00 \overline{1})$ reduces by $\sim 9.5 \%$ at the phase transition on heating and returns to its original dimensions on cooling back to RT (see Supporting Information, Video_S1 and S2). During the cooling cycle between the temperatures $(360-330 \mathrm{~K})$, corresponding to the III $\rightarrow$ II transition, limited changes are observed. However,

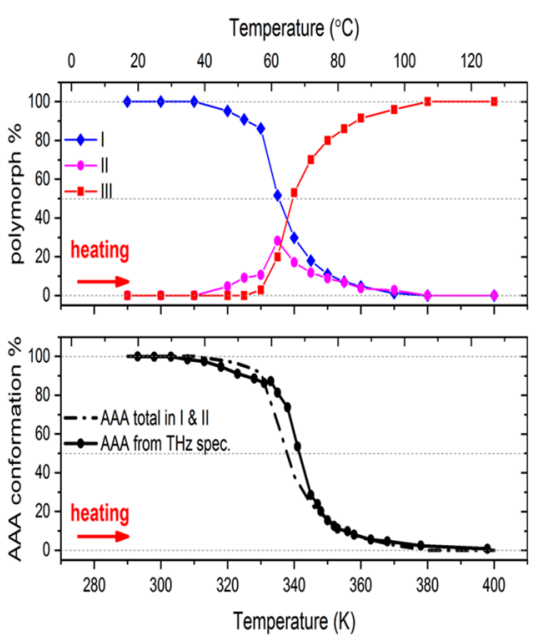

(a)
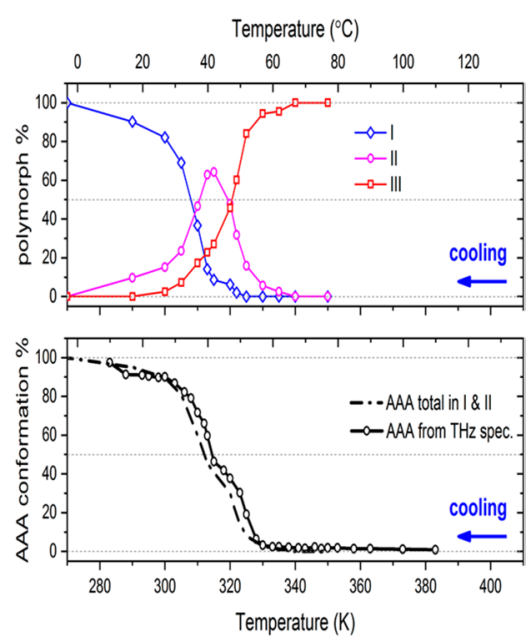

(b)

Figure 7. Percentage of polymorphs I (blue), II (magenta), and III (red) of DES as a function of temperature, from quantitative variable temperature PXRD, compared to and percentage of AAA conformations analyzed by THz-Raman during the (a) heating and (b) cooling cycle. 

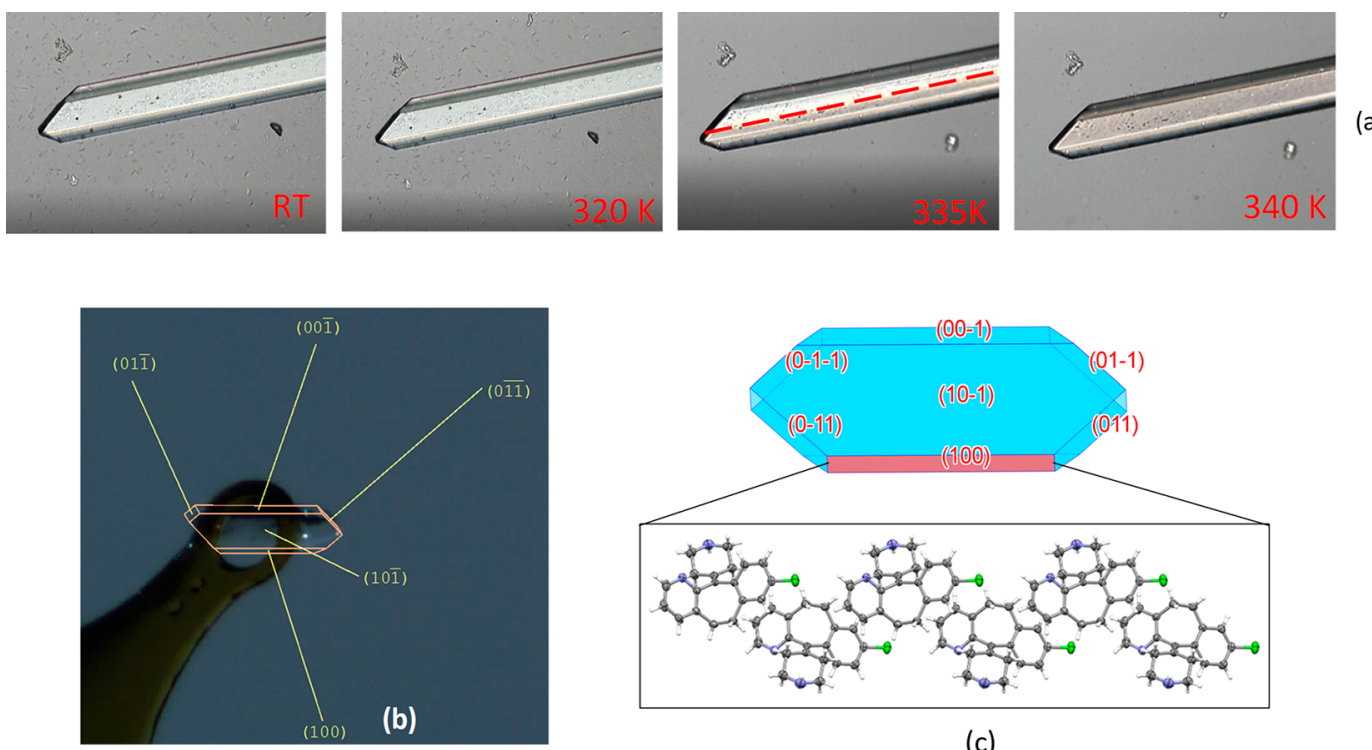

(c)

Figure 8. (a) Microscopic image of a DES crystal immersed in silicon oil on cycling through the phase transitions. The red dashed line indicates the movement of the visible phase boundary between DES II $\rightarrow$ I. (b) SXRD face indexing of representative single crystal used in hot-stage analysis. (c) Crystal packing arrangement on the (100) face.

upon further cooling through the II $\rightarrow$ I transformation between 320 and $300 \mathrm{~K}$, the crystal shape changes visibly as the wavefront propagates through the crystal with a change in relative intensity of the light transmitted through the crystal. The propagation of a discernible wavefront occurred in a number of crystals of different sizes at a range of heating/ cooling rates. The speed of the propagating wavefront during both the heating ( $\rightarrow$ II and/or II $\rightarrow$ III) and cooling cycles (II-I) was estimated to be in the range of $0.17-0.35 \mu \mathrm{m} / \mathrm{s}$, which showed some dependence on the heating/cooling rate as well as the crystal size. The speed of the wavefront of transformation in all cases is several orders of magnitude slower than the displacive second order transformations ${ }^{64}$ observed in metals and alloys. ${ }^{65}$ The reversible phase transitions and shape changing effects occur with complete retention of the crystal orientation and morphology. ${ }^{23}$

If the crystals are heated when exposed in air, cracks appear accompanied by a visible propagation of a transformation interface in the bulk of the crystal, followed by small movements of the crystal as it transforms to form III (Supporting Information Figure S2, Supporting Information, Video S3). There are again no observable optical phenomenon during the cooling III $\rightarrow$ II transformation. However, upon further cooling, a transverse wavefront was observed during the II $\rightarrow$ I transformation. The numerous cracks observed during the heating cycle are possibly due to strains from temperature gradients, arising from the less uniform heat transfer in the absence of silicon oil. The estimated speed of the wavefront in air-exposed crystals is generally faster $(\sim 37 \mu \mathrm{m} / \mathrm{s})$ compared to crystals immersed in silicon oil. The slight movement of the crystal (see Supporting Information Video_S3) is a demonstration of the thermosalient effect, although is not as strong as those observed in other jumping crystals, ${ }^{66-68}$ where crystals jump off the surface due to the sudden release of strain or elastic energy following a phase transformation.

The reversible shape change in the I $\rightarrow$ II $\rightarrow$ III transition is most apparent at the dominant (10 $\overline{1})$ face of the DES crystal, defining the width of the crystal as viewed in Figure 9. The crystal packing arrangement in the $(10 \overline{1})$ plane shows that the

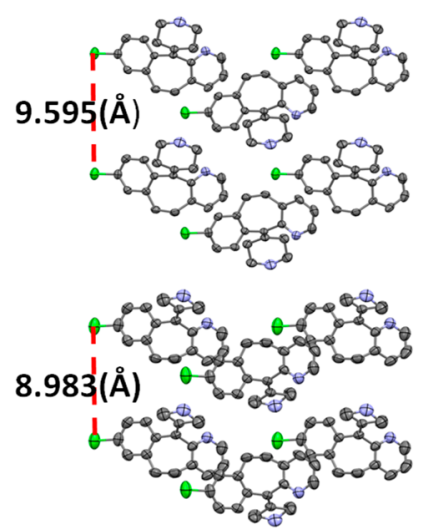

(a)
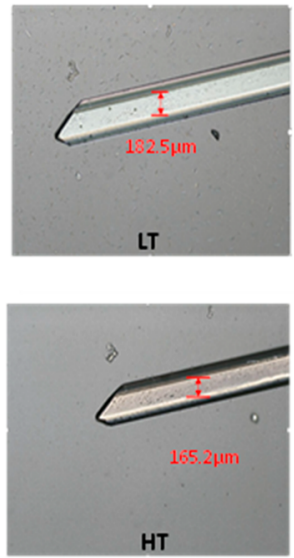

(b)
Figure 9. (a) Distance between chlorine atoms $\left(d_{\mathrm{Cl}-\mathrm{Cl}}\right)$ in the $(10 \overline{1})$ plane measured in form I and form III. (b) Photographs of crystal deformation at low and high temperatures. The crystal contracts by around $9.5 \%$ on the $(10 \overline{1})$ face, which is a consequence of the change in $d_{\mathrm{Cl}-\mathrm{Cl}}$ distance in the $(10 \overline{1})$ plane.

distance between two chlorine atoms $\left(d_{\mathrm{Cl}-\mathrm{Cl}}\right)$ decreases by $0.976 \AA$ or $9.8 \%$, from 9.959 (2) $\AA$ in form I to $8.983 \AA$ in form III (Figure 9a). This change in $d_{\mathrm{Cl}-\mathrm{Cl}}$ distance following the conformational flipping of the piperidine ring in DES results in a contraction in the crystal size by $\sim 9.5 \%$ (from $182.5 \rightarrow 165.2$ $\mu \mathrm{m}$; Figure $9 \mathrm{~b}$ and Supporting Information, Figure S3) as observed in hot-stage microscopy. The transformed crystal at high temperature reverts back to the original shape when cooled to RT. While molecular crystals that reversibly change shape due to order-disorder ${ }^{69}$ phase transformations ${ }^{14,70-73}$ have been reported, DES is the first case of macroscopic shapechanging organic crystal resulting from significant conformational changes. The macroscopic and reversible shape deformation in DES crystals is not instantaneous, as would be observed in second-order shuffle-type transformations; rather, it is induced locally and consistently via nucleation on 
the $(00 \overline{1})$ face, and growth spreads gradually over the entire crystal within a small temperature window via propagation of the transformation wavefront. While the exact cause of the reproducible directional wavefront remains unknown, the sluggishness of the wavefront and the associated shape changing effect can be attributed to the changes in molecular conformation and intermolecular interactions in the crystal.

\section{DISCUSSION}

The experimental observations have structurally characterized the high-temperature form (form III) of DES as a conformational polymorph and have shown that there is an ordered intermediate phase (form II) with CSP showing that further polymorphs are unlikely. Periodic DFT-D calculations put the lattice energy and density of form II midway between those of form I and III. The three polymorphs have nearly identical packing with a definite orientational relationship between the parent and daughter phases (Supporting Information, Section 1.2.5). While there are significant conformational changes in the piperidine moiety of DES, there are only relatively subtle changes in the intermolecular distances between neighboring molecules, preserving their relative orientation and packing. This is reminiscent of diffusionless phase transformations ${ }^{71}$ which in metals and inorganics preserves the interatomic distances between successive phases. However, unlike atoms in metal crystals, which only need to be specified with interatomic distances, molecules in molecular crystals can change their conformations and orientations. Attempts to fit these transitions neatly into any existing categories of diffusionless transformations ${ }^{74}$ remain difficult.

The single-crystal to single-crystal transformations in DES are first-order processes proceeding via nucleation and growth, manifested as heat-transfer events in DSC and their considerable hysteresis. The sluggish-moving wave fronts observed during the phase changes also do not fit into any mechanism involving a concerted movement within the whole crystal. The wave fronts in DES always initiate on the (100/ $00 \overline{1})$ face and propagate in the [10 $\overline{1}]$ direction of the crystal, suggesting a single nucleation event initiated by the flipping of the piperidine moiety of DES molecules on the (001) face. Additionally, there is a consistent orientation relationship between the parent and daughter lattices, probably the result of epitaxial growth of the latter. ${ }^{49,50,75,76}$ Previous examples of concerted movements in molecular crystals have been linked to martensitic type transformations. Anwar et al. used molecular dynamics to report concerted bilayer displacements in the $\beta \rightarrow$ $\alpha$ topotactic phase transformation in DL-norleucine. ${ }^{77}$ Yao et al. reported cooperative movements of $\left[\mathrm{Ni}^{\mathrm{II}}(\mathrm{en})_{3}\right]^{2+}$ cations due to $90^{\circ}$ rotation of the oxalate ion in $\left[\mathrm{Ni}^{\mathrm{iI}}(\mathrm{en})_{3}\right]$ (ox) complex. ${ }^{78}$ Martensitic type transformations were also reported in superelastic crystals of terephthalamide ${ }^{79}$ and 3,5-difluorobenzoic acid. ${ }^{80}$ While DES polymorphs exhibit an orientational relationship and the crystals display reversible shape changing effects, the transformation speed in DES, which depends on the crystal size and quality, and its environment (air/silicon oil), is several orders of magnitude slower than the speed of elastic waves observed in martensitic type and thermosalient phase transformations. ${ }^{66-68,81}$ This is consistent with the phonon mode calculations on DES showing that it is not a phase transition mediated by a soft mode. These observations emphasize that cooperative motion, most commonly associated with second-order transitions, is compatible with nucleation and growth theory for the mechanism of solid- sate transitions. ${ }^{82}$ The ability of DES to undergo the conformational change of flipping the piperidine ring in the solid state, presumably aided by the two steps (I $\rightarrow$ II $\rightarrow$ III) in a reversible shape-changing manner, shows how remarkably accommodating weakly bound pharmaceutical crystals can be to structural transformation.

The thermally induced transformations between the three polymorphs, investigated by several in-situ variable-temperature studies, revealed the ease with which the polymorphic conversions can occur in DES. The transformation temperatures identified for transition to DES II and III are routinely accessible during the drying and granulation processing steps, for example. If the drug product was exposed to temperatures above the transition temperature, the reversible shape change of the crystallites could affect tablet integrity and associated performance attributes.

\section{CONCLUSION}

The transformations in DES provide a rare chance to explore and understand the mechanism of a reversible, two-step singlecrystal-to-single-crystal phase transition between conformational polymorphs. The transition is seen to initiate on specific facets of the crystal, suggesting a single surface nucleation event that propagates the transformation as an observable wavefront across the crystal. The observations contrast vividly with phase transitions observed in inorganic or metallic crystals, or indeed rigid molecular crystals where displacive positional shifts bring about phase transitions. While DES bears some similarities to transformation in ciclopirox, ${ }^{22}$ the conformational change observed in these DES phase transitions is unique. The ring inversion process in DES is too complex to occur via a low-energy phonon softening as observed in organic jumping crystals of 1,2,4,5-tetrabromobenzene. ${ }^{83,84}$ Employing a hierarchy of experimental techniques coupled with computational approaches, we clearly demonstrate that the two reversible phase transformations observed in DES are first-order transformations involving the concerted movement of molecules within the crystal. The phase transitions of DES highlight the limitations in current classifications of solid-state phase transitions, historically derived from inorganic systems, and call for special care when these are applied to the rich and diverse behavior of solid-solid phase transitions of organic compounds. ${ }^{23,85}$

\section{ASSOCIATED CONTENT}

\section{SI Supporting Information}

The Supporting Information is available free of charge at https://pubs.acs.org/doi/10.1021/acs.cgd.9b01522.

Full details of all the experimental and computational modeling (PDF)

Videos of hot-stage microscopy of DES phase transformation (MP4-1, MP4-2, MP4)

\section{Accession Codes}

CCDC 1963618-1963621 (DES I at $80 \mathrm{~K}$, DES III at $350 \mathrm{~K}$, DES I at $293 \mathrm{~K}$, DES II at $335 \mathrm{~K}$, respectively) contain the supplementary crystallographic data for this paper. These data can be obtained free of charge via www.ccdc.cam.ac.uk/ data_request/cif, or by emailing data_request@ccdc.cam.ac. uk, or by contacting The Cambridge Crystallographic Data Centre, 12 Union Road, Cambridge CB2 1EZ, UK; fax: +44 1223 336033. The reduced unit cell parameters of DES II and III were transformed to the reported values in CIF files using 
the transformation matrices $\left[\begin{array}{lllllllll}1 & 0 & 1 & 0 & 1 & 0 & \overline{1} & 0 & 0\end{array}\right]$ and $\left[\begin{array}{llllll}\overline{1} & 0 & 0 & 0 & \overline{1} & 0\end{array}\right.$ $\left.\begin{array}{lll}1 & 0 & 1\end{array}\right]$ respectively to have consistent orientation between all three polymorphs.

\section{AUTHOR INFORMATION}

\section{Corresponding Author}

Alastair J. Florence - Strathclyde Institute of Pharmacy and Biomedical Sciences and EPSRC Future Continuous Manufacturing and Advanced Crystallisation Hub, University of

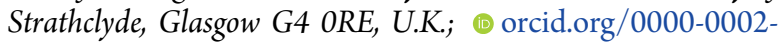
9706-8364; Email: alastair.florence@strath.ac.uk

\section{Authors}

Vijay K. Srirambhatla - Strathclyde Institute of Pharmacy and Biomedical Sciences and EPSRC Future Continuous Manufacturing and Advanced Crystallisation Hub, University of Strathclyde, Glasgow G4 ORE, U.K.; (1) orcid.org/0000-0002$4492-7567$

Rui Guo - Department of Chemistry, University College London, London WC1H 0AJ, U.K.; (1) orcid.org/0000-0002-11294716

Daniel M. Dawson - School of Chemistry, EaStCHEM and St Andrews Centre for Magnetic Resonance, University of St Andrews, North Haugh KY16 9ST, U.K.

Sarah L. Price - Department of Chemistry, University College London, London WC1H 0AJ, U.K.; $\odot$ orcid.org/0000-00021230-7427

Complete contact information is available at:

https://pubs.acs.org/10.1021/acs.cgd.9b01522

\section{Funding}

This work was supported by EPSRC (EP/K039229/1). ARCHER time was provided via our membership of the UK's HEC Materials Chemistry Consortium, which is funded by EPSRC (EP/L000202).

\section{Notes}

The authors declare no competing financial interest.

\section{ACKNOWLEDGMENTS}

We thank Profs. Pantelides and Adjiman for the use of CrystalPredictor and CrystalOptimizer codes, Prof. Keith Refson for help with using CASTEP for phonon calculations, and Prof. Bruce M. Foxman for fruitful discussion and for the TOPO v 4.40 code.

\section{ABBREVIATIONS}

DES, desloratadine; DSC, differential scanning calorimetry; VT-PXRD, variable temperature X-ray powder diffraction; VTSS-NMR, variable temperature solid state nuclear magnetic resonance spectroscopy; $\mathrm{THz}$, terahertz; NDBA, N-substituted dibenzazepine; VT-SXRD, variable temperature single crystal $\mathrm{X}$-ray diffraction; DABCO, 1,4-diazabicyclo[2.2.2] octane

\section{REFERENCES}

(1) Bernstein, J. Polymorphism in Molecular Crystals; Clarendon Press: Oxford, 2002.

(2) Brittain, H. G. Polymorphism in Pharmaceutical Solids; Marcel Dekker AG: Basel, Switzerland, 1999.

(3) Cruz-Cabeza, A. J.; Bernstein, J. Conformational Polymorphism. Chem. Rev. 2014, 114, 2170-2191.

(4) Cruz-Cabeza, A. J.; Reutzel-Edens, S. M.; Bernstein, J. Facts and fictions about polymorphism. Chem. Soc. Rev. 2015, 44, 8619-8635.
(5) Nangia, A. Conformational polymorphism in organic crystals. Acc. Chem. Res. 2008, 41, 595-604.

(6) Sanphui, P.; Goud, N. R.; Khandavilli, U. B. R.; Bhanoth, S.; Nangia, A. New polymorphs of curcumin. Chem. Commun. 2011, 47, 5013-5015.

(7) Yu, L. Polymorphism in Molecular Solids: An Extraordinary System of Red, Orange, and Yellow Crystals. Acc. Chem. Res. 2010, 43, 1257-1266.

(8) Braga, D.; Grepioni, F.; Chelazzi, L.; Nanna, S.; Rubini, K.; Curzi, M.; Giaffreda, S. L.; Saxell, H. E.; Bratz, M.; Chiodo, T. Bentazon: Effect of Additives on the Crystallization of Pure and Mixed Polymorphic Forms of a Commercial Herbicide. Cryst. Growth Des. 2014, 14, 5729-5736.

(9) Yang, J.; Zhu, X.; Hu, C. T.; Qiu, M.; Zhu, Q.; Ward, M. D.; Kahr, B. Inverse Correlation between Lethality and Thermodynamic Stability of Contact Insecticide Polymorphs. Cryst. Growth Des. 2019, 19, 1839-1844.

(10) Ting, V. P.; Schmidtmann, M.; Wilson, C. C.; Weller, M. T. Cisplatin: Polymorphism and Structural Insights into an Important Chemotherapeutic Drug. Angew. Chem., Int. Ed. 2010, 49, 94089411.

(11) Price, S. L. Is zeroth order crystal structure prediction (CSP 0) coming to maturity? What should we aim for in an ideal crystal structure prediction code? Faraday Discuss. 2018, 211, 9-30.

(12) Sato, O. Dynamic molecular crystals with switchable physical properties. Nat. Chem. 2016, 8, 644-644.

(13) Vogelsberg, C. S.; Garcia-Garibay, M. A. Crystalline molecular machines: function, phase order, dimensionality, and composition. Chem. Soc. Rev. 2012, 41, 1892-1910.

(14) Ahmed, E.; Karothu, D. P.; Naumov, P. Crystal Adaptronics: Mechanically Reconfigurable Elastic and Superelastic Molecular Crystals. Angew. Chem., Int. Ed. 2018, 57, 8837-8846.

(15) Browne, W. R.; Feringa, B. L. Making molecular machines work. Nat. Nanotechnol. 2006, 1, 25-35.

(16) Naumov, P.; Chizhik, S.; Panda, M. K.; Nath, N. K.; Boldyreva, E. Mechanically Responsive Molecular Crystals. Chem. Rev. 2015, $115,12440-12490$.

(17) Smets, M.; Pitak, M.; Cadden, J.; Kip, V.; de Wijs, G.; van Eck, E.; Tinnemans, P.; Meekes, H.; Vlieg, E.; Coles, S.; Cuppen, H. The Rich Solid-State Phase Behavior of DL-Aminoheptanoic Acid: Five Polymorphic Forms and Their Phase Transitions. Cryst. Growth Des. 2018, 18, 242-252.

(18) Ehrenfest, P. Phase conversions in a general and enhanced sense, classified according to the specific singularities of the thermodynamic potential. P. K. Akad. Wet-Amsterd. 1933, 36, 153157.

(19) Buerger, M. J. In Phase Transformations in Solids; Smoluchowski, R.; Mayer, J. E.; Weyl, W. A., Eds.; John Wiley \& Son: New York, 1951.

(20) Ubbelohde, A. R. Thermal transformations in solids. Q. Rev., Chem. Soc. 1957, 11, 246-272.

(21) Herbstein, F. On the mechanism of some first-order enantiotropic solid-state phase transitions: from Simon through Ubbelohde to Mnyukh. Acta Crystallogr., Sect. B: Struct. Sci. 2006, 62, 341-383.

(22) Brandel, C.; Cartigny, Y.; Couvrat, N.; Eusebio, M. E. S.; Canotilho, J.; Petit, S.; Coquerel, G. Mechanisms of Reversible Phase Transitions in Molecular Crystals: Case of Ciclopirox. Chem. Mater. 2015, 27, 6360-6373.

(23) Byrn, S. R.; Curtin, D. Y.; Paul, I. C. X-ray crystal structures of the yellow and white forms of dimethyl 3,6-dichloro-2,5-dihydroxyterephthalate and a study of the conversion of the yellow form to the white form in the solid state. J. Am. Chem. Soc. 1972, 94, 890-898.

(24) DuBuske, L. M. Review of desloratadine for the treatment of allergic rhinitis, chronic idiopathic urticaria and allergic inflammatory disorders. Expert Opin. Pharmacother. 2005, 6, 2511-2523.

(25) Bhatt, P. M.; Desiraju, G. R. Form I of desloratadine, a tricyclic antihistamine. Acta Crystallogr., Sect. C: Cryst. Struct. Commun. 2006, 62, o362-o363. 
(26) Ainurofiq, A.; Mauludin, R.; Mudhakir, D.; Umeda, D.; Soewandhi, S. N.; Putra, O. D.; Yonemochi, E. Improving mechanical properties of desloratadine via multicomponent crystal formation. Eur. J. Pharm. Sci. 2018, 111, 65-72.

(27) Toth, Z. G.; Gyollai, V.; Kovacsne-Mezei, A.; Szabo, C.; Aronhime, J.; Singer, C., Processes for preparation of polymorphic forms of desloratadine. US Patent Application 2004/0242619 A1, 2004.

(28) Frisch, M. J.; Trucks, G. W.; Schlegel, H. B.; Scuseria, G. E.; Robb, M. A.; Cheeseman, J. R.; Scalmani, G.; Barone, V.; Mennucci, B.; Petersson, G. A.; Nakatsuji, H.; Caricato, M.; Li, X.; Hratchian, H. P.; Izmaylov, A. F.; Bloino, J.; Zheng, G.; Sonnenberg, J. L.; Hada, M.; Ehara, M.; Toyota, K.; Fukuda, R.; Hasegawa, J.; Ishida, M.; Nakajima, T.; Honda, Y.; Kitao, O.; Nakai, H.; Vreven, T.; Montgomery, J. A., Jr; Peralta, J. E.; Ogliaro, F.; Bearpark, M.; Heyd, J. J.; Brothers, E.; Kudin, K. N.; Staroverov, V. N.; Kobayashi, R.; Normand, J.; Raghavachari, K.; Rendell, A.; Burant, J. C.; Iyengar, S. S.; Tomasi, J.; Cossi, M.; Rega, N.; Millam, J. M.; Klene, M.; Knox, J. E.; Cross, J. B.; Bakken, V.; Adamo, C.; Jaramillo, J.; Gomperts, R.; Stratmann, R. E.; Yazyev, O.; Austin, A. J.; Cammi, R.; Pomelli, C.; Ochterski, J. W.; Martin, R. L.; Morokuma, K.; Zakrzewski, V. G.; Voth, G. A.; Salvador, P.; Dannenberg, J. J.; Dapprich, S.; Daniels, A. D.; Farkas, Ö.; Foresman, J. B.; Ortiz, J. V.; Cioslowski, J.; Fox, D. J. Gaussian 09, Revision D.01; Gaussian, Inc.: Wallingford, CT, 2009.

(29) Stone, A. J. Distributed multipole analysis: Stability for large basis sets. J. Chem. Theory Comput. 2005, 1, 1128-1132.

(30) Karamertzanis, P. G.; Pantelides, C. C. Ab initio crystal structure prediction - I. Rigid molecules. J. Comput. Chem. 2005, 26, 304-324.

(31) Kazantsev, A. V.; Karamertzanis, P. G.; Adjiman, C. S.; Pantelides, C. C. Efficient Handling of Molecular Flexibility in Lattice Energy Minimization of Organic Crystals. J. Chem. Theory Comput. 2011, 7, 1998-2016.

(32) Price, S. L.; Leslie, M.; Welch, G. W. A.; Habgood, M.; Price, L. S.; Karamertzanis, P. G.; Day, G. M. Modelling Organic Crystal Structures using Distributed Multipole and Polarizability-Based Model Intermolecular Potentials. Phys. Chem. Chem. Phys. 2010, 12, 8478-8490.

(33) Perdew, J. P.; Ruzsinszky, A.; Tao, J. M.; Staroverov, V. N.; Scuseria, G. E.; Csonka, G. I. Prescription for the design and selection of density functional approximations: More constraint satisfaction with fewer fits. J. Chem. Phys. 2005, 123, 062201.

(34) Tkatchenko, A.; Scheffler, M. Accurate Molecular Van Der Waals Interactions from Ground-State Electron Density and FreeAtom Reference Data. Phys. Rev. Lett. 2009, 102, 073005.

(35) Grimme, S. Accurate description of van der Waals complexes by density functional theory including empirical corrections. J. Comput. Chem. 2004, 25, 1463-1473.

(36) Ambrosetti, A.; Reilly, A. M.; DiStasio, R. A.; Tkatchenko, A. Long-range correlation energy calculated from coupled atomic response functions. J. Chem. Phys. 2014, 140, 18 A508.

(37) Clark, S. J.; Segall, M. D.; Pickard, C. J.; Hasnip, P. J.; Probert, M. J.; Refson, K.; Payne, M. C. First principles methods using CASTEP. Z. Kristallogr. - Cryst. Mater. 2005, 220, 567-570.

(38) Rietveld, H. M. A Profile Refinement Method for Nuclear and Magnetic Structures. J. Appl. Crystallogr. 1969, 2, 65-71.

(39) APEX3, SAINT and SADABS; Bruker AXS Inc.: Madison, Wisconsin, USA, 2016.

(40) Sheldrick, G. M. SHELXT - Integrated space-group and crystalstructure determination. Acta Crystallogr., Sect. A: Found. Adv. 2015, $71,3-8$.

(41) Betteridge, P. W.; Carruthers, J. R.; Cooper, R. I.; Prout, K.; Watkin, D. J. CRYSTALS version 12: software for guided crystal structure analysis. J. Appl. Crystallogr. 2003, 36, 1487-1487.

(42) Haw, J. F.; Crook, R. A.; Crosby, R. C. Solid-solid phase transitions for temperature calibration in magic-angle spinning. $J$. Magn. Reson. (1969-1992) 1986, 66, 551-554.
(43) Skibsted, J.; Jakobsen, H. J. Variable-Temperature 87Rb MagicAngle Spinning NMR Spectroscopy of Inorganic Rubidium Salts. J. Phys. Chem. A 1999, 103, 7958-7971.

(44) Price, S. L. Predicting crystal structures of organic compounds. Chem. Soc. Rev. 2014, 43, 2098-2111.

(45) Pulido, A.; Chen, L. J.; Kaczorowski, T.; Holden, D.; Little, M. A.; Chong, S. Y.; Slater, B. J.; McMahon, D. P.; Bonillo, B.; Stackhouse, C. J.; Stephenson, A.; Kane, C. M.; Clowes, R.; Hasell, T.; Cooper, A. I.; Day, G. M. Functional materials discovery using energystructure-function maps. Nature 2017, 543, 657-664.

(46) Price, S. L.; Braun, D. E.; Reutzel-Edens, S. M. Can computed crystal energy landscapes help understand pharmaceutical solids? Chem. Commun. 2016, 52, 7065-7077.

(47) Florence, A. J. Approaches to High-Throughput Physical Form Screening and Discovery. In Polymorphism in Pharmaceutical Solids, 2nd ed.; Brittain, H. G., Ed.; Informa Helthcare: New York: London, 2009.

(48) Arlin, J. B.; Price, L. S.; Price, S. L.; Florence, A. J. A strategy for producing predicted polymorphs: catemeric carbamazepine form V. Chem. Commun. 2011, 47, 7074-7076.

(49) Neumann, M. A.; van de Streek, J.; Fabbiani, F. P. A.; Hidber, P.; Grassmann, O. Combined crystal structure prediction and highpressure crystallization in rational pharmaceutical polymorph screening. Nat. Commun. 2015, 6, 7793.

(50) Srirambhatla, V. K.; Guo, R.; Price, S. L.; Florence, A. J. Isomorphous template induced crystallisation: a robust method for the targeted crystallisation of computationally predicted metastable polymorphs. Chem. Commun. 2016, 52, 7384-7386.

(51) Case, D. H.; Srirambhatla, V. K.; Guo, R.; Watson, R. E.; Price, L. S.; Polyzois, H.; Cockcroft, J. K.; Florence, A. J.; Tocher, D. A.; Price, S. L. Successful Computationally Directed Templating of Metastable Pharmaceutical Polymorphs. Cryst. Growth Des. 2018, 18, $5322-5331$

(52) Burger, A.; Ramberger, R. Polymorphism of Pharmaceuticals and Other Molecular-Crystals. 1. Theory of Thermodynamic Rules. Microchim. Acta 1979, 72, 259-271.

(53) Verma, A. R.; Krishna, P. Polymorphism and Polytypism in Crystals; John Wiley and Sons: 1966.

(54) Foxman, B. M. TOPO: A Program for Analysis of Topotactic Relationshps, v4.40; Brandeis University: USA, 2017.

(55) McIntosh, A. I.; Yang, B.; Goldup, S. M.; Watkinson, M.; Donnan, R. S. Terahertz spectroscopy: a powerful new tool for the chemical sciences? Chem. Soc. Rev. 2012, 41, 2072-2082.

(56) King, M. D.; Buchanan, W. D.; Korter, T. M. Application of London-type dispersion corrections to the solid-state density functional theory simulation of the terahertz spectra of crystalline pharmaceuticals. Phys. Chem. Chem. Phys. 2011, 13, 4250-4259.

(57) Hédoux, A.; Guinet, Y.; Derollez, P.; Willart, J.-F.; Capet, F.; Descamps, M. Pressure-induced transformations and high-pressure behaviour in cyanoadamantane plastic crystal. J. Phys.: Condens. Matter 2003, 15, 8647-8661.

(58) Day, G. M.; Price, S. L.; Leslie, M. Atomistic calculations of phonon frequencies and thermodynamic quantities for crystals of rigid organic molecules. J. Phys. Chem. B 2003, 107, 10919-10933.

(59) Beran, G. J. O. Modeling Polymorphic Molecular Crystals with Electronic Structure Theory. Chem. Rev. 2016, 116, 5567-5613.

(60) Brandenburg, J. G.; Potticary, J.; Sparkes, H. A.; Price, S. L.; Hall, S. R. Thermal Expansion of Carbamazepine: Systematic Crystallographic Measurements Challenge Quantum Chemical Calculations. J. Phys. Chem. Lett. 2017, 8, 4319-4324.

(61) Jmol: An Open-Source Java Viewer for Chemical Structures in 3D. http://www.jmol.org/.

(62) Krumhansl, J. A.; Gooding, R. J. Structural phase transitions with little phonon softening and first-order character. Phys. Rev. B: Condens. Matter Mater. Phys. 1989, 39, 3047-3053.

(63) Ruggiero, M. T.; Zhang, W.; Bond, A. D.; Mittleman, D. M.; Zeitler, J. A. Uncovering the Connection Between Low-Frequency Dynamics and Phase Transformation Phenomena in Molecular Solids. Phys. Rev. Lett. 2018, 120, 196002. 
(64) Porter, D. A.; Easterling, K. E.; Sherif, M. Y. Phase Transformations in Metals and Alloys, 3rd ed.; CRC Press: Boca Raton: London, 2009.

(65) Tanaka, Y.; Himuro, Y.; Kainuma, R.; Sutou, Y.; Omori, T.; Ishida, K. Ferrous Polycrystalline Shape-Memory Alloy Showing Huge Superelasticity. Science 2010, 327, 1488-1490.

(66) Skoko, Z.; Zamir, S.; Naumov, P.; Bernstein, J. The Thermosalient Phenomenon. "Jumping Crystals" and Crystal Chemistry of the Anticholinergic Agent Oxitropium Bromide. J. Am. Chem. Soc. 2010, 132, 14191-14202.

(67) Nath, N. K.; Panda, M. K.; Sahoo, S. C.; Naumov, P. Thermally induced and photoinduced mechanical effects in molecular single crystals-a revival. CrystEngComm 2014, 16, 1850-1858.

(68) Sahoo, S. C.; Panda, M. K.; Nath, N. K.; Naumov, P. Biomimetic Crystalline Actuators: Structure-Kinematic Aspects of the Self-Actuation and Motility of Thermosalient Crystals. J. Am. Chem. Soc. 2013, 135, 12241-12251.

(69) Chung, H.; Dudenko, D.; Zhang, F.; D’Avino, G.; Ruzié, C.; Richard, A.; Schweicher, G.; Cornil, J.; Beljonne, D.; Geerts, Y.; Diao, Y. Rotator side chains trigger cooperative transition for shape and function memory effect in organic semiconductors. Nat. Commun. 2018, 9, 278.

(70) Liu, G.; Liu, J.; Liu, Y.; Tao, X. Oriented Single-Crystal-toSingle-Crystal Phase Transition with Dramatic Changes in the Dimensions of Crystals. J. Am. Chem. Soc. 2014, 136, 590-593.

(71) Karothu, D. P.; Weston, J.; Desta, I. T.; Naumov, P. ShapeMemory and Self-Healing Effects in Mechanosalient Molecular Crystals. J. Am. Chem. Soc. 2016, 138, 13298-13306.

(72) Koshima, H.; Ojima, N.; Uchimoto, H. Mechanical Motion of Azobenzene Crystals upon Photoirradiation. J. Am. Chem. Soc. 2009, 131, 6890-6891.

(73) Kobatake, S.; Takami, S.; Muto, H.; Ishikawa, T.; Irie, M. Rapid and reversible shape changes of molecular crystals on photoirradiation. Nature 2007, 446, 778-778.

(74) Kostorz, G. Phase Transformations in Materials; Wiley-VCH: Weinheim, 2001.

(75) Sosso, G. C.; Chen, J.; Cox, S. J.; Fitzner, M.; Pedevilla, P.; Zen, A.; Michaelides, A. Crystal Nucleation in Liquids: Open Questions and Future Challenges in Molecular Dynamics Simulations. Chem. Rev. 2016, 116, 7078-7116.

(76) Jiang, Q.; Shtukenberg, A. G.; Ward, M. D.; Hu, C. NonTopotactic Phase Transformations in Single Crystals of $\beta$-Glycine. Cryst. Growth Des. 2015, 15, 2568-2573.

(77) Anwar, J.; Tuble, S. C.; Kendrick, J. Concerted molecular displacements in a thermally-induced solid-state transformation in crystals of DL-norleucine. J. Am. Chem. Soc. 2007, 129, 2542-2547. (78) Yao, Z.-S.; Mito, M.; Kamachi, T.; Shiota, Y.; Yoshizawa, K.; Azuma, N.; Miyazaki, Y.; Takahashi, K.; Zhang, K.; Nakanishi, T.; Kang, S.; Kanegawa, S.; Sato, O. Molecular motor-driven abrupt anisotropic shape change in a single crystal of a $\mathrm{Ni}$ complex. Nat. Chem. 2014, 6, 1079-1079.

(79) Takamizawa, S.; Miyamoto, Y. Superelastic Organic Crystals. Angew. Chem. 2014, 126, 7090-7093.

(80) Takamizawa, S.; Takasaki, Y. Superelastic Shape Recovery of Mechanically Twinned 3,5-Difluorobenzoic Acid Crystals. Angew. Chem., Int. Ed. 2015, 54, 4815-4817.

(81) Loncaric, I.; Popovic, J.; Despoja, V.; Burazer, S.; Grgicevic, I.; Popovic, D.; Skoko, Z. Reversible Thermosalient Effect of $\mathrm{N}^{\prime}-2$ Propylidene-4-hydroxybenzohydrazide Accompanied by an Immense Negative Compressibility: Structural and Theoretical Arguments Aiming toward the Elucidation of Jumping Phenomenon. Cryst. Growth Des. 2017, 17, 4445-4453.

(82) Smets, M. M. H. Exploring the mechanism of solid-state phase transitions in molecular crystals. Ph.D. Dissertation. Radboud University Nijmegen, Nijmegen, The Netherlands, 2018.

(83) Ko, J.-H.; Lee, K.-S.; Chandra Sahoo, S.; Naumov, P. Isomorphous phase transition of 1,2,4,5-tetrabromobenzene jumping crystals studied by Brillouin light scattering. Solid State Commun. 2013, 173, 46-50.
(84) Zakharov, B. A.; Michalchuk, A. A. L.; Morrison, C. A.; Boldyreva, E. V. Anisotropic lattice softening near the structural phase transition in the thermosalient crystal 1,2,4,5-tetrabromobenzene. Phys. Chem. Chem. Phys. 2018, 20, 8523-8532.

(85) Anwar, J.; Zahn, D. Polymorphic phase transitions: Macroscopic theory and molecular simulation. Adv. Drug Delivery Rev. 2017, $117,47-70$. 